Journal of Science and technology, Vol 37, No. 2 (2017), pp110-125 110

(C) 2017 Kwame Nkrumah University of Science and Technology (KNUST)

http://dx.doi.org/10.4314/just.v37i2.9

RESEARCH PAPER

\title{
EXPLORATION OF THE SHAPE DRAWING TOOLS IN MICROSOFT WORD FOR FOSTERING IDEA DEVELOPMENT IN THE GHANAIAN INDIGENOUS KENTE WEAVING INDUSTRY
}

\author{
G. Y. Annum \\ Department of Painting and Sculpture, KNUST, Kumasi \\ Email: anngodam@yahoo.co.uk
}

\begin{abstract}
The advancement of computer technology for digital artistry in this $21^{\text {st }}$ century has availed newmedia technologies for enhancing design practices in technical and vocational studies through the development of sophisticated graphic-application software. Unfortunately, these software are very challenging to learn and employ for creative design practice especially at the Basic and Senior High School levels of education in Ghana. Microsoft Office word belongs to the category of general-purpose application software, developed principally for word processing. Unfortunately, many of its users are oblivious of its capabilities for creative motif and pattern designing. It is embedded with shape designing tools that can be manipulated and modified to create intricate patterns for advancing variety of design concepts. The researcher has explored these tools and adopted them for creating fascinating kente design concepts, based on the design-based research approach. This paper therefore presents a descriptive account of how to use angular and linear shapes in Microsoft Word to create motifs and patterns to develop ideas for kente designing that can be employed by Ghanaian indigenous kente designers to foster idea development to enhance their trade.
\end{abstract}

Keywords: New-media technologies; Graphic application software; Microsoft office word; Creative pattern designing; Ghanaian indigenous kente designers.

\section{INTRODUCTION}

The popularity of the traditional Kente cloth is unquestionable. It is Ghana's topmost creative traditional wear respected for its intricate symbolic design. It has recently gained global acceptance and for special ceremonies in many educational institutions across the world. There is substantial evidence to show that in the United States many African-American high school and college graduates wear kente cloth over their graduation gowns. This practice is also very popular with historically black Greek letter fraternities and sororities. It has also been documented that African American students hold special ceremonies called "Donning of the Kente" where stoles are presented to the graduates (Wales 2015). This opens the door of opportunities for designers and weavers to improve their designing skills in order to create more innovative motifs and patterns that will enhance the outlook of kente fabrics. This will obviously enhance the quality of designs that 


\section{Annum}

enhance the outlook of kente fabrics. This will obviously enhance the quality of designs that characterize the kente cloth produced in modern times to break monotony.

The computer as a technological device comes with graphic application software including Photoshop and CorelDraw for fostering Creative Art teaching and practice in various art disciplines. These application software are often very difficult to learn and employ for product design and general art practice. Even though Microsoft Word (MS Word) (one of the most popular software on all windows operating system computers) is classified under general-purpose application software for word processing (O'Brien, 2003), it is embedded with basic tools for drawing geometric shapes. The researcher has explored these tools in MS Word 2007 and adopted them to produce fascinating fabric designs, which can be employed by Art teachers especially at the Junior High School level to introduce their students to kente designing skills. The objective is to help Ghanaian students most especially those whose parents are in the kente weaving industry to develop creative skills for idea development in kente weaving that will equip them with the capacity to support their parents to boost their industry.

In this paper therefore, the researcher has demonstrate MS Word design possibilities based on the Design-based Research (DBR) methodology concepts (van den Akker, 1999), (Easterday, Lewis $\&$ Gerber, 2014) and employed the Descriptive method (Best, 1981) to reveal procedures for creating motifs and patterns for fascinating idea development in kente weaving. As the most widely used application programme by scholars in academia for text-based documentation a description of MS Word shape designing capabilities will obviously equip many textile designers who often rely on sophisticated software before coming out with design models, with the basic technical knowhow for idea development in kente weaving.

\section{MS WORD DESIGNING CAPABILITIES}

The popularity of MS word among the generalpurpose applications software programmes is unquestionable (Annum, 2013). It is widely known for its word processing capabilities for creating, formatting, editing, saving and printing any type of word-based document such as letters, report, memo, resumes, research papers, email message and even web pages (Haag, Perry, Parker \& Wells, 2002). MS Word 2007 or any of the higher versions is embedded with geometric shape tools for illustration. These tools can be manipulated to create motifs and patterns for idea development in fabric designing especially in the areas of 'batik' and weaving technologies. They can produce fascinating effects that compares with designs from some of the most preferred advanced graphic application software including Photoshop and CorelDraw, which are complex and difficult to learn even at the tertiary level of education.

Unfortunately, many textile designers are oblivious of these capabilities beyond word editing. This became evident at a 'NADKIDEC' international conference held in 2017 under the auspices of the Faculty of Art of the College of Art and Built Environment in KNUST when the researcher run a workshop to reveal MS Word designing capabilities.

MS Word shape tools are very easy to handle. It only requires rudimentary manipulative skills for transforming them into interesting and intricate kente designs. The shapes are in the 'illustration group' under the insert ribbon in MS Word and are made of lines, basic shapes, block arrows, flowchart, callouts, stars and banners (Poole, 2010) (Fig .1).

When any of these shapes is drawn, the format ribbon (Fig 2) will be opened to provide the formatting tools for manipulating and modifying the shape. A shape can be resize, copied, pasted, moved, dragged and dropped to a new location. The principal attributes of a shape, regarding its 'outline' and 'fill', can also be altered by assigning patterns, textures or gradient effect to enhance the visual effect of the shape. Shadow and 3-D effect can also be assigned to a shape. The 'arrange tools' under the format ribbon enables multiple shapes to be grouped and ungrouped, rotated, flipped horizontally or vertically, sent backward or brought forward to reorder the shapes. 


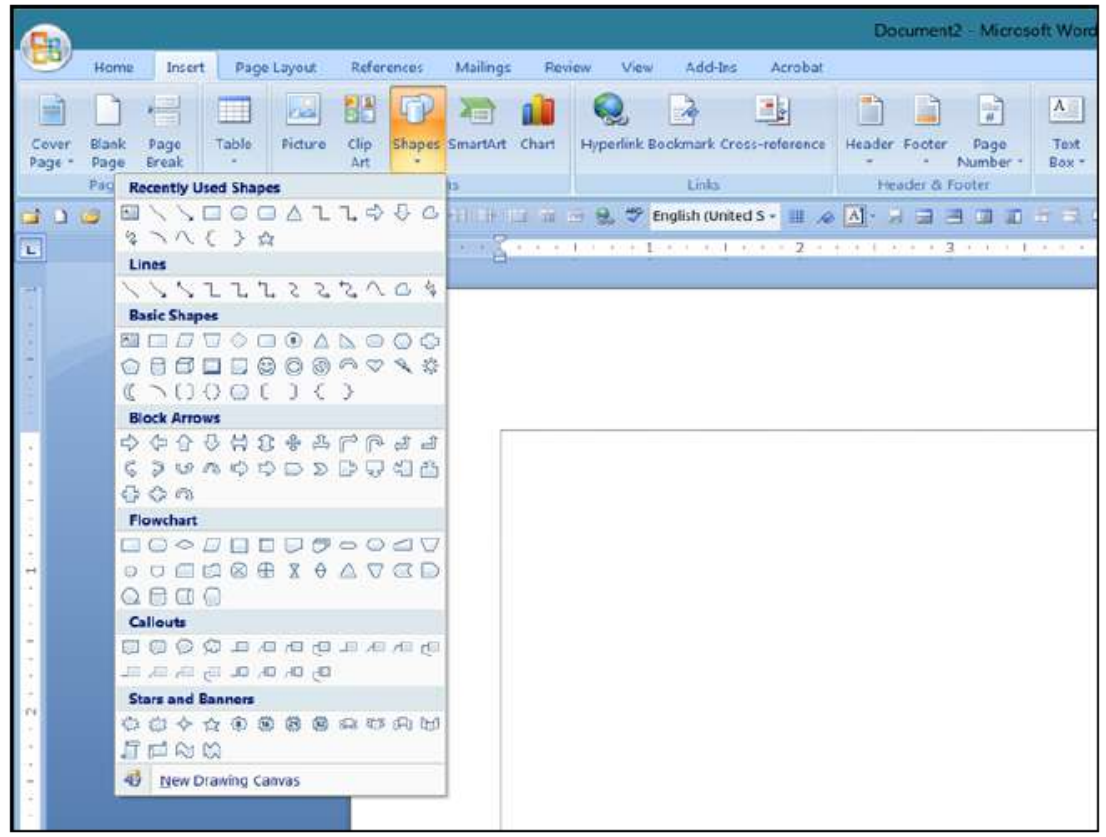

Fig 1: Drop-down menu of the shape tools

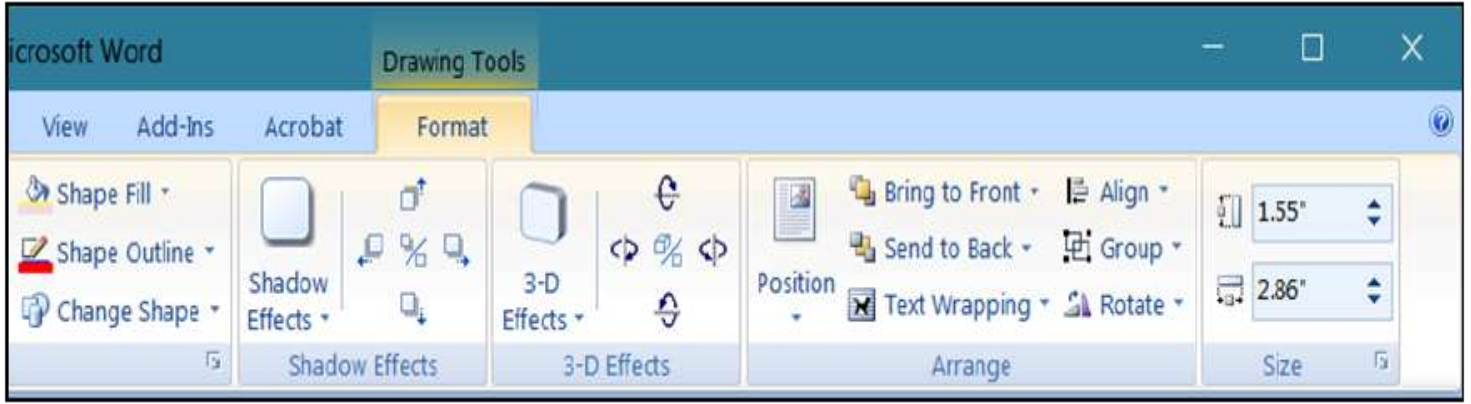

Fig 2: The format ribbon

\section{FORMATTING SCHEMES}

It is important at this stage to explain the formatting schemes that were used to manipulate two geometric shapes; 'rectangle' and 'parallelogram' in this exercise which includes:

1. Drawing a shape

2. Resizing a shape

3. Changing the shape fill effect

4. Changing an outline effect

5. Rotating a shape
6. Flipping a shape

7. Grouping shapes

8. Ungrouping shapes

9. Moving a shape up or down in a stack

Drawing a shape

To draw a shape like a rectangle

1. Select the rectangle tool in the shape menu under the Illustration group in the Insert ribbon. The cursor will immediately change into a plus 


\section{Annum}

sign.

2. Click and hold down on the mouse at anywhere on the paper and drag the 'plus sign' cursor to insert the rectangle shape. Once the shape is drawn, Sizing handles (small circles and squares that appear at the corners and sides of a selected object) (Fig 3) will show to indicate that a shape has been selected. Once the shape is selected, the format ribbon (Fig 2) will automatically open to provide tools for formatting the rectangle. You can also drag these handles to change the size of the shape.

\section{Resizing a shape}

The sizing handles are used to manually resize a shape to desired dimensions. On the other hand, under the size group in the format ribbon which is automatically opened after a shape is selected, the height and width dimensions of the shape can be edited by changing the values in the editable boxes.

To manually resize a shape

1. Click the shape to be resized.

2. To increase or decrease the size in one or more directions, drag a sizing handle away from or toward the center, while doing one of the following:

a. To keep the center of the shape in the same place, press and hold CTRL while dragging the sizing handle.

b. To maintain the shape's proportions, press and hold SHIFT while dragging the diagonal sizing handle.

c. To both maintain the shape's proportions and keep its center in the same place, press and hold both CTRL and SHIFT while you drag the diagonal sizing handle.

\section{To resize to an exact height and width}

1. Click to select the shape.

2.Under Drawing Tools, on the Format ribbon, in the Size group, click the Dialog Box Launcher

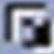

3. On the Size tab, under Scale clear the Lock aspect ratio check box

4. Enter the desired measurements into the Height and Width absolute boxes.

5. Confirm to the dialogue box.

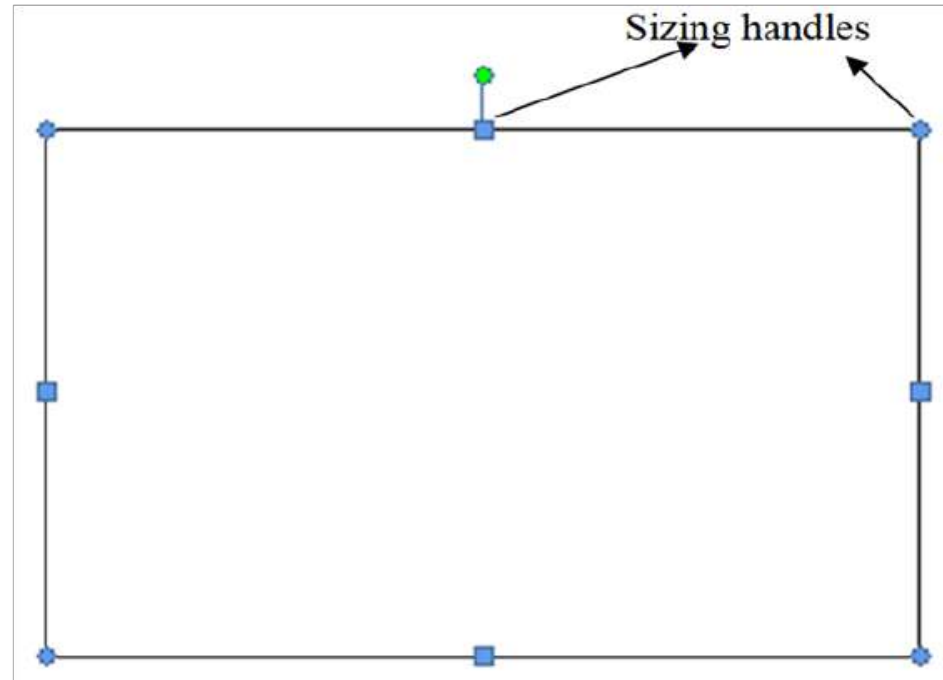

Fig 3: Sizing handles 
To resize to an exact proportion

1. Click to select the shape.

2. Under Drawing Tools, on the Format ribbon, in the Size group, click the Dialog Box Launcher.

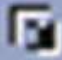

3. On the Size tab, under Scale, clear the Lock aspect ratio check box

4. Under Scale, enter the desired percentages in the Height and Width boxes.

5. Confirm to the dialogue box.

To change the shape fill colour

1. Click to select the shape

2. To add the same fill to multiple shapes, click the first shape, and then press and hold CTRL on the keyboard while you click the other shapes.
3. Under Drawing Tools, on the Format tab, in the Shape Styles group, click the arrow next to Shape Fill to drop down the themes colour (Fig 4) and then do one of the following:

a. Click the colour that you want to add or change a fill colour or click No Fill to choose no colour.

b. Click More Fill Colours and then either click the colour that you want on the Standard tab, or mix your own colour on the Custom tab to change to a colour that is not in the in the theme colours

\section{Changing the shape fill effect}

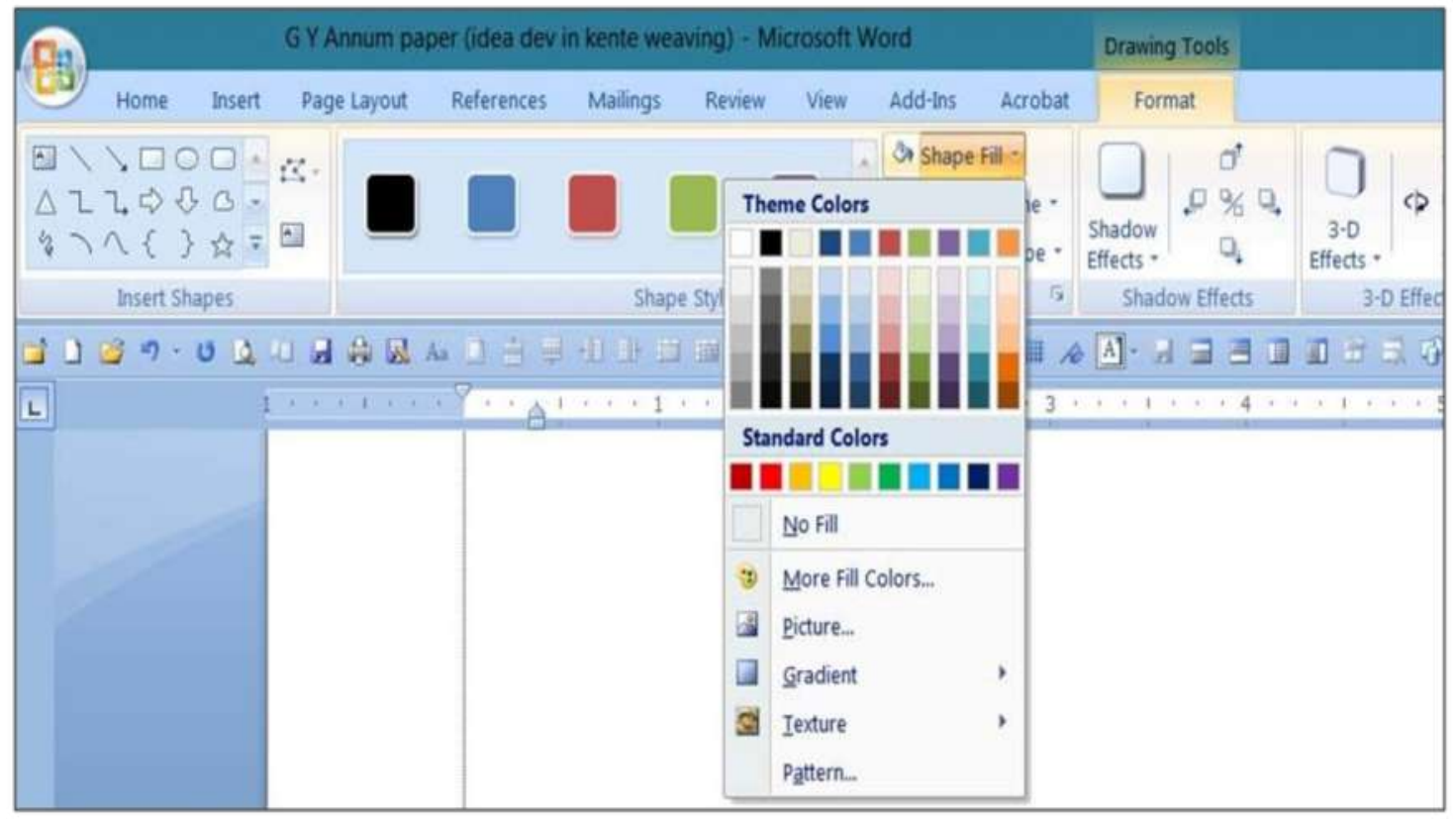

Fig 4: Shape fill colours 


\section{Annum}

c. Click Pattem to open the fill effects dialogue box. Under the pattern tab, select a foreground and a background colour of your choice and then select either dark horizontal or the dark vertical pattern effect to replicate a weave effect.
Custom tab to change to a colour that is not in the theme colours.

To change an outline thickness

a. Point to Weight and then click the thickness

\section{Changing an Outline Effect}

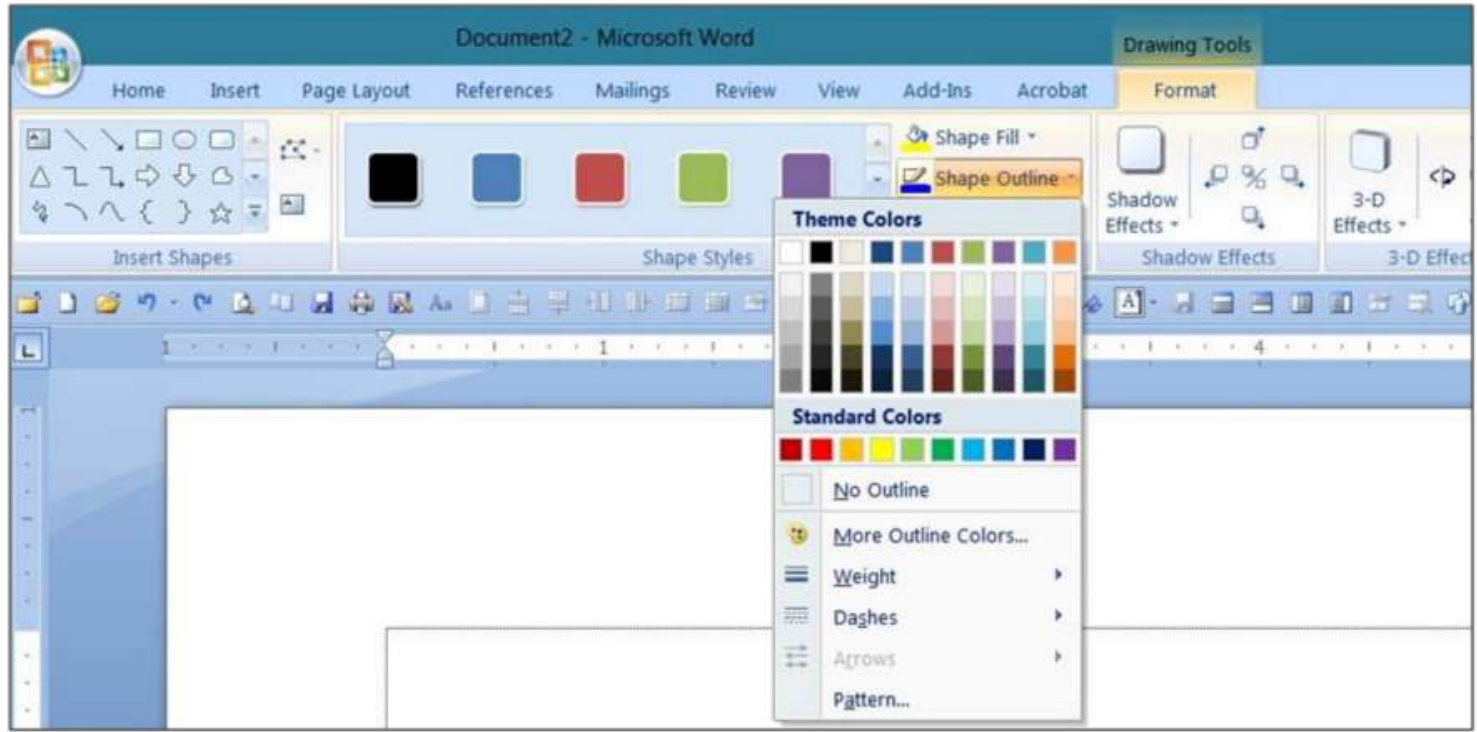

Fig 5: Shape outline colours

To change an outline colour

1. Click to select the shape

2. Under Drawing Tools, on the Format ribbon, in the Shape Styles group, click the arrow next to Shape Outline to drop down the themes colour (Fig 5) and then do one of the following:

a. Click the colour that you want to add or change an outline colour.

b. Click No Outline to choose no colour.

c. Click More Outline Colours, and then either click the colour that you want on the Standard tab, or mix your own colour on the that you want to add or change the thickness of the outline,

b. Click More Lines and then choose the options that you want to customize the thickness,

c. Point to Dashes and then click the style that you want to add or change the outline to dots or dashes,

d. Click More Lines and then choose the options that you want to customize the style.

e. Click Pattem and then click the options that you want to add or change the pattern. 


\section{Rotating a Shape}

Click the shape that you want to rotate:

1. Drag the rotation handle in the direction that you want to rotate the shape. Note; to constrain the rotation to 15 degree angles, press and hold SHIFT while you drag the rotation handle (fig 6).

2. To specify an exact rotation, under Drawing Tools, on the Format ribbon, in the Arrange
2. Click the duplicated shape. In the Arrange group under the Format ribbon, click Rotate, and then do one of the following:

a. To reverse the object vertically, click Flip Vertical.

b. To reverse the object horizontally, click Flip Horizontal.

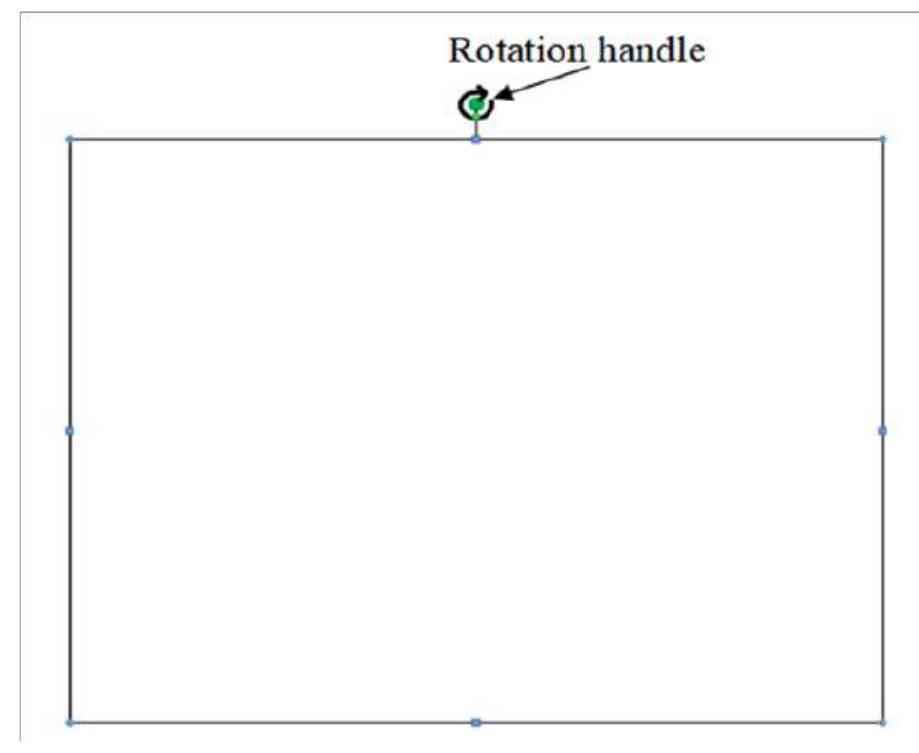

Fig 6: Rotation handle

group, click Rotate, click More Rotation Options, and then on the Size tab, under Rotate, enter the amount that you want to rotate the picture in the Rotation box.

3. To rotate 90 degrees to the left or 90 degrees to the right, click the shape. In the Arrange group, click Rotate, and then select the option that fits your intention.

\section{Flipping a Shape (reversing an image)}

Flipping a shape is to create a reverse image of the shape.

1. To create a mirror image of a shape, make a copy of it and drag it to another position.

\section{Grouping Shapes}

The group tool is used to bind multiple objects into a single unit.

To group multiple shapes, select the shapes. In the Arrange group under the Format ribbon, click the grouping symbol Group. After you group the shapes, you can continue to select any single shape within the group by first selecting the group, and then clicking the individual shape to select.

\section{Ungrouping Shapes}

To ungroup a group of shapes (for example, if you want to move a group but leave one shape behind or make extensive changes to one shape 


\section{Annum}

without changing the other shapes), Select the group that you want to ungroup. Under Drawing Tools, on the Format ribbon, in the Arrange group, click grouping symbol '†; , and then click Ungroup .

Moving a shape up or down in a stack

If you have, shapes, or other objects that are grouped or stacked on top of each other, you can move objects or groups of objects up or down within the stack one layer at a time, or you can move them to the top or bottom of a stack in one move.

Click the shape that you want to move up or down in the stack. In the Arrange group under the format ribbon, do one of the following:

1. To bring a shape one-step closer to the front, click the arrow next to Bring to Front, and then click Bring Forward.

2. To bring the shape to the front, click the arrow next to Bring to Front, and then click Bring to Front.

3. To send the shape one-step toward the back, click the arrow next to Send to Back, and then click Send Backward.

4. To send the shape to the back, click the arrow next to Send to Back, and then click Send to Back.

You also have the option of moving the shape in front of or behind a text. After you click the arrow next to Bring to Front, click Bring in Front of Text. Conver sely, to move the object behind your text, click the arrow next to Send to Back, and then click Send Behind Text.

\section{ESSENTIALS FOR DESIGNING}

The Ghanaian indigenous kente fabric is dominated with angular and linear shapes hence the appropriate geometric shapes (Fig 7) to use include line, rectangle, parallelogram, diamond, triangle, trapezium, hexagon and the cross shape. Placing the cursor over the shape will pop up a tool tip to show the name of the tool.

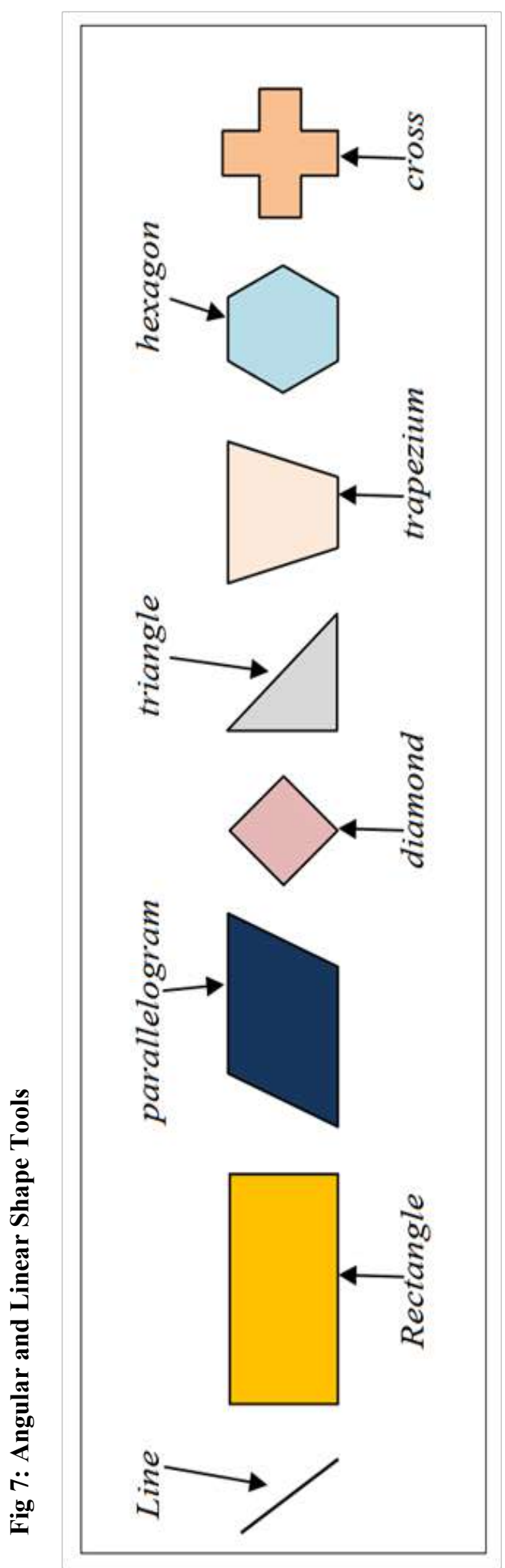

Journal of Science and Technology C KNUST August 2017 
Two of the above geometric shapes were used to create the kente design in fig 8 , made up of four composite motifs. These are the rectangle and the parallelogram. The techniques employed apply to any of the other geometric shapes.

\section{Designing techniques}

The formatting schemes discussed above formed the bases of the researcher's designing techniques. Regarding designing surface, one can work directly on the default paper in the document area of MS word programme or insert a 'New Drawing Canvas' on the paper. In this exercise, the designing was done directly on the paper ( $A 4$ size) in the document area instead of working on a drawing canvas. The margins (top, bottom, left and right) of the paper were all set at 0 from the page setup dialogue box, in the units that has been customized for the software. This widened the working area of the paper so that objects inserted in line with the text begun from the margins.
When a specific size of shape is inserted in the correct orientation, the outline fill is first removed before assigning a desirable colour fill to it. Then either the dark horizontal or the dark vertical pattern effect is assigned to replicate a loom weave effect. It is from this primary shape that copies could be repeated, aligned and grouped in either a positive or a reverse form to become a motif.

\section{RESULTS AND DISCUSSION \\ Designing Composite Motif 1 (Fig 10) \\ Step 1: The orange base colour}

A rectangle measuring 4" wide x 2.6" high was drawn and assigned an orange fill pattern colour with no outline colour to serve as the background for composite motif 1 (Fig 9).

\section{Step 2: The zigzag motif}

The parallelogram measuring 1.2" wide $\mathrm{x}$ 0.26 " high with a blue-black fill colour and NO' outline colour was inserted to the top left
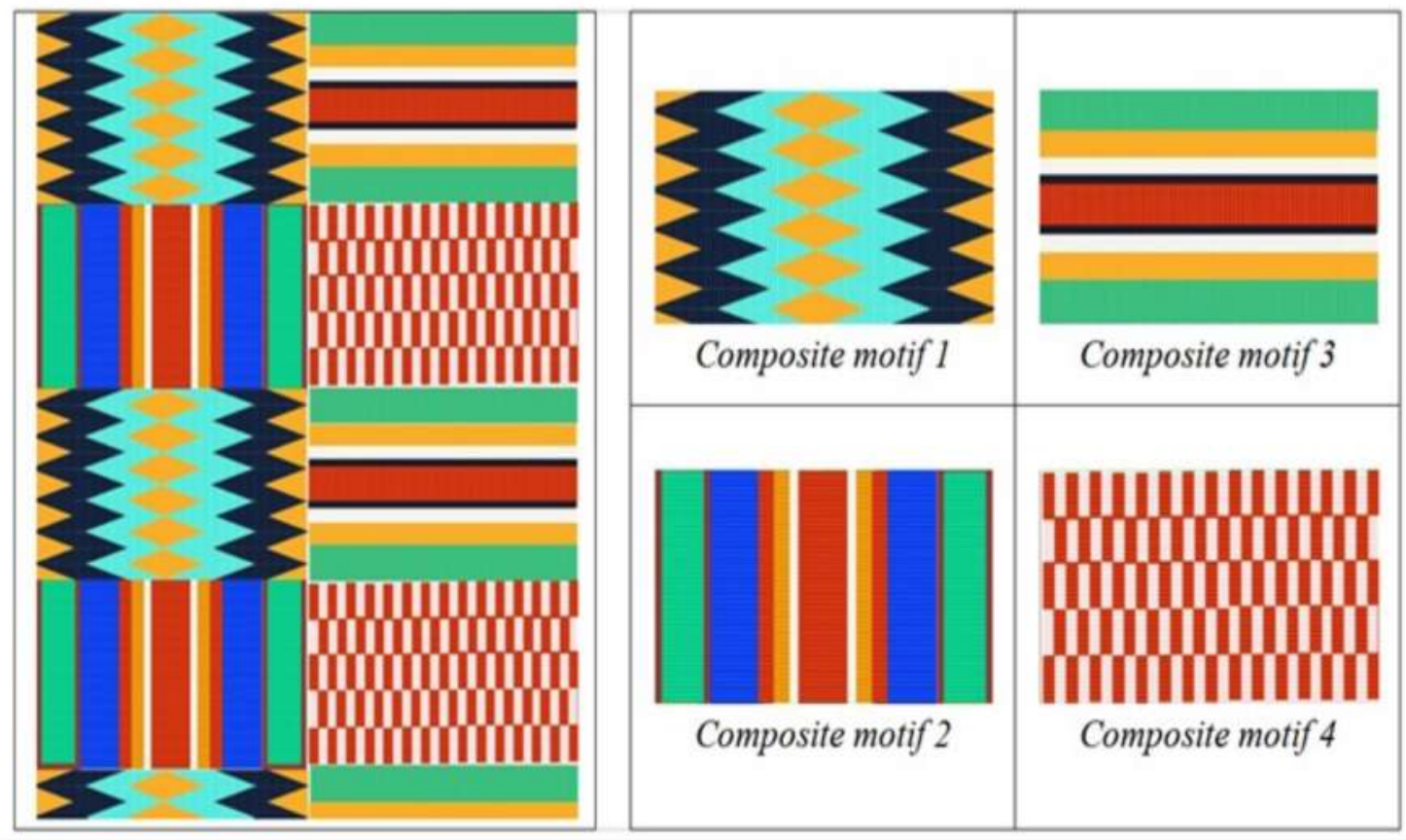

Fig 8: Sample kente design 


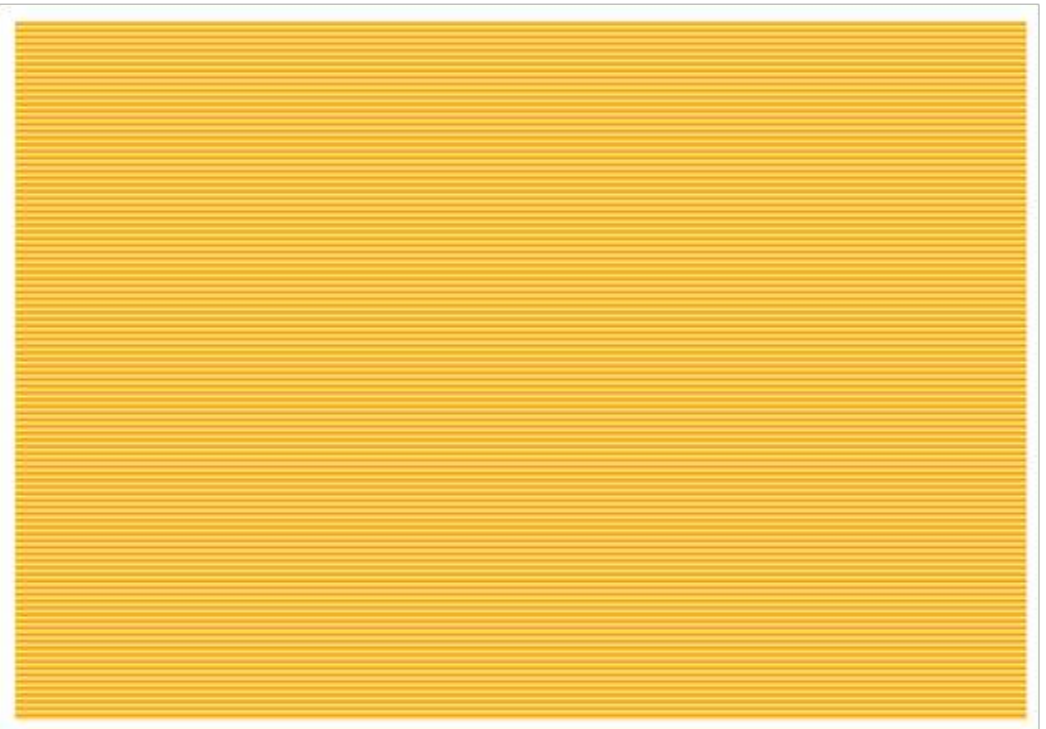

Fig 9: Background colour for composite motif 1

'corner of the orange background as the primary shape.

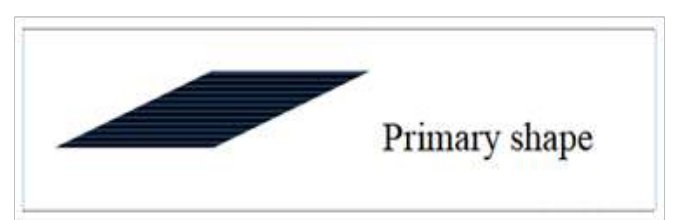

2. The primary shape was copied and flipped horizontally to create a reversed image before aligning it to the base line of the primary shape.

3. The two shapes were tightly aligned and

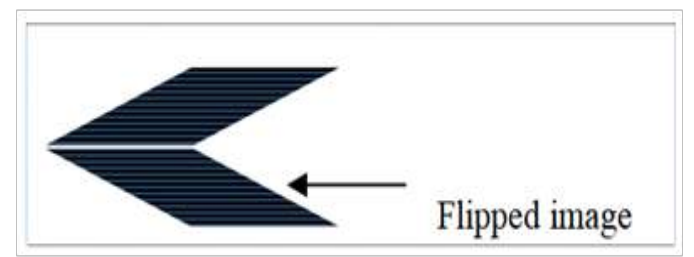

grouped (motif 1) and another copy created (motif 2) before tightly aligning to the base line of the motif 1 .

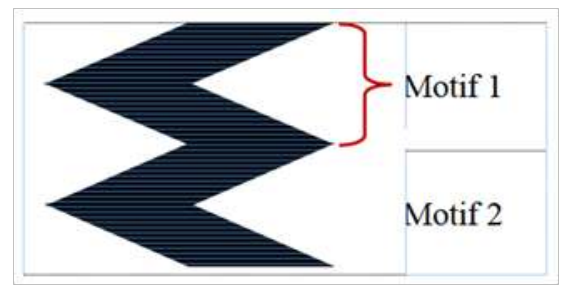

Step 3: Duplicating the zigzag motif

1. In all, five copies of 'motif 1' and a copy of the primary shape were created and tightly aligned vertically before grouping them into the blue-black zigzag motif (Motif 3).

2. 'Motif 3' was duplicated and the fill colour was changed to sky blue (Motif 4). This was aligned to the right side of motif 3 in its positive form.

3. The two zigzag motifs (Motif $3 \& 4$ ) were regrouped and a copy was pasted before flipping horizontally to create a reversed image (Motif 5) and moved to the right edge of the orange background. 


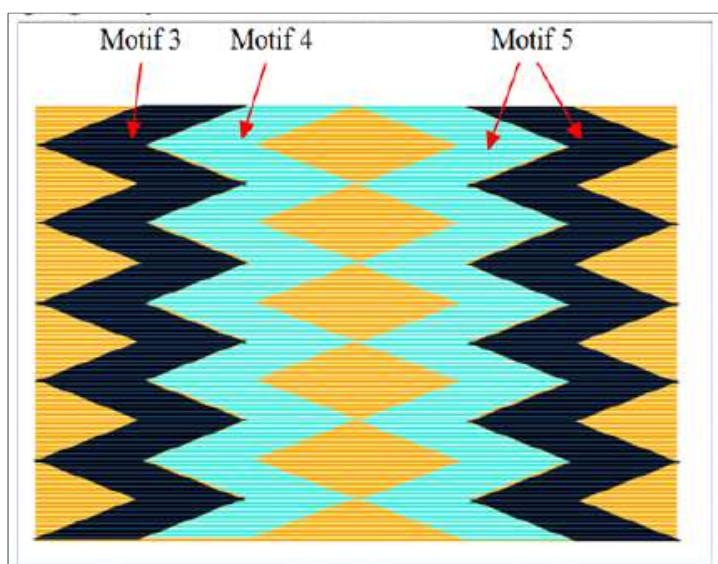

Step 4: Creating the composite motif 1

Finally, all the motifs and the orange background shape were selected and grouped together into the composite motif 1 (Fig 10).

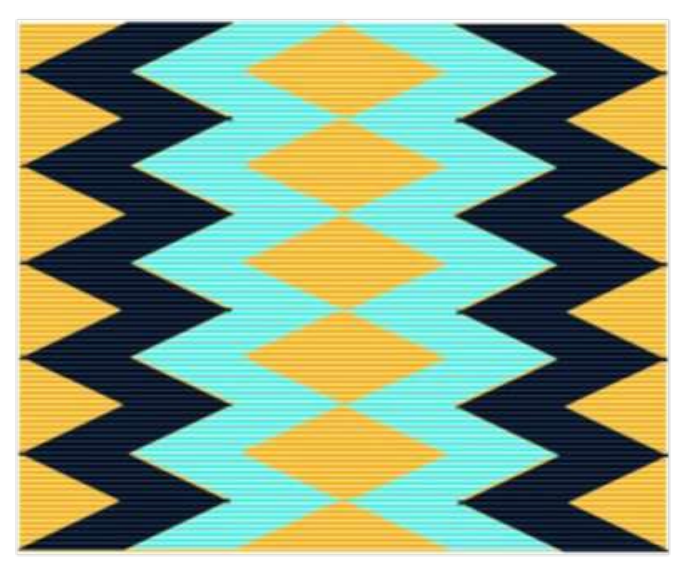

Fig 10: Composite motif 1

\section{Designing Composite Motif 2 (Fig 11)}

Only the rectangular shape was used to design motif 2 .

The height of the rectangle measured 2.6 inches for all the shapes inserted. Only the width were varied. Seven shapes were created with different fill colours but without outline fill. The pattern effects too were also the same.
Step 1: Inserting eight rectangular shapes

Eight rectangular shapes of varied width measurement but similar height measurement of 2.6 inches were inserted and compactly aligned horizontally.

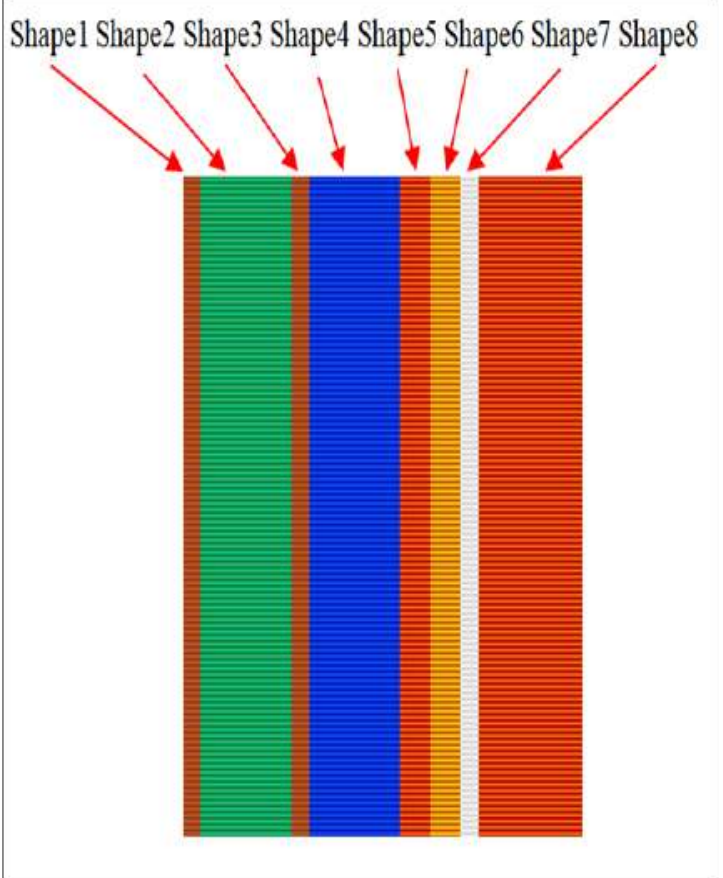




\section{Annum}

Step 2: Creating the reverse motif of the first seven rectangular shapes

The first seven rectangular shapes were collectively selected and grouped (group 1) before inserting a copy and flipping it horizontally to the right side of the eighth rectangular shape (group 2).

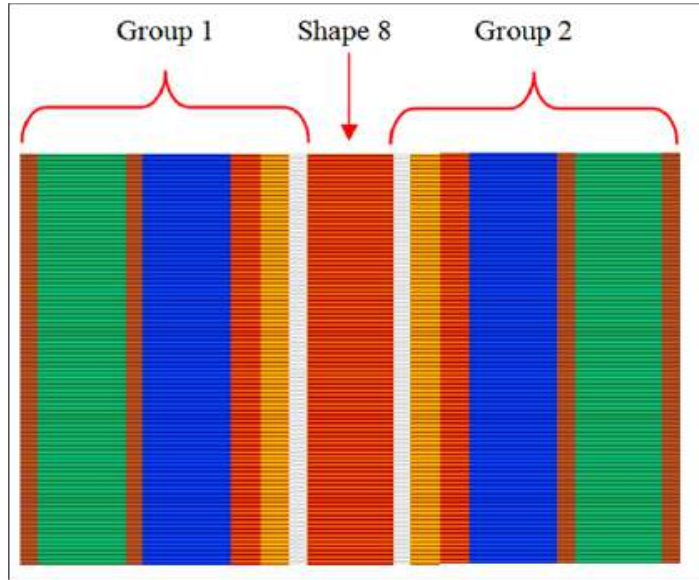

Step 3: Creating the composite motif 2

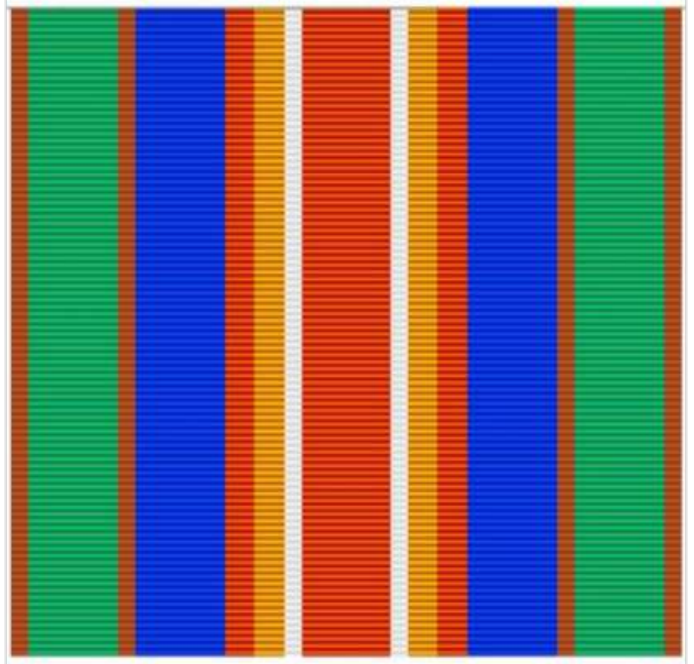

Fig 11: Composite motif 2

Finally, the two groups and the eighth shape were selected and grouped together into the composite motif 2 (Fig 11).
Designing Composite Motif 3 (Fig 12)

Only the rectangular shape was used to design motif 3 .

The width of the rectangle measured the same (4 inches) for all the shapes inserted. Only the heights were varied. Nine shapes were created with different fill colours but without outline fill. The pattern effects too were also the same.

Step 1: Inserting five rectangular shapes

Five rectangular shapes of varied height measurement but similar width measurement of 4 inches were inserted and tightly aligned vertically. The colours were varied as a matter of choice even though the same pattern effect was used for all the shapes.

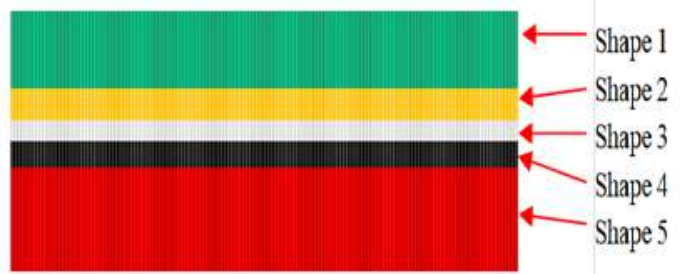

Step 2: Creating the reverse motif of the first four rectangular shapes

The first four rectangular shapes were collectively selected and grouped (group 1) before inserting a copy and flipping it vertically (group 2) to the bottom side of shape 5 .

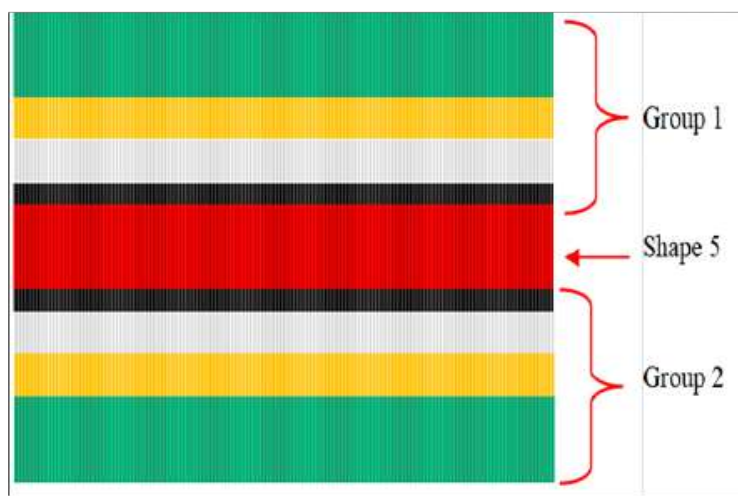


Step 3: Creating the composite motif 3

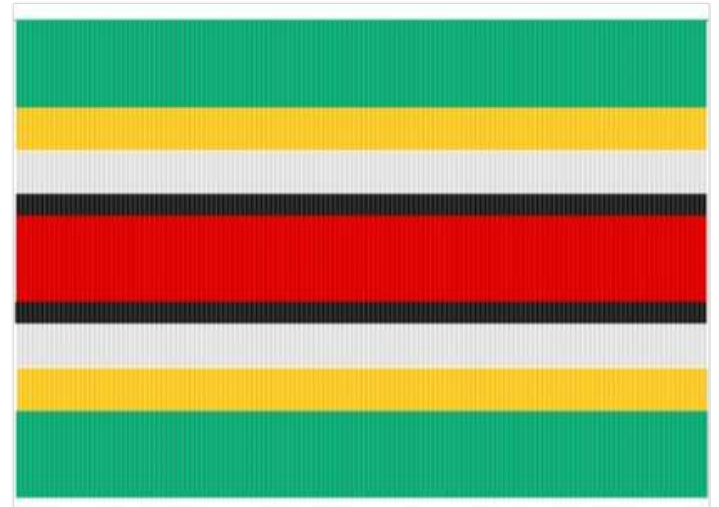

Fig 12: Composite motif 3

Finally, the 2 groups and shape 5 were selected and grouped together into the composite motif 3 (Fig 12).

\section{Designing Composite Motif 4 (Fig 13)}

Only the rectangular shape was used to design motif 4.

Two fill colours were used without outline fill (light pink as the base colour and brown as the primary motif).

Step 1: The light pink base colour

A rectangle measuring 4" wide x 2.6" high was drawn and assigned a light pink fill pattern colour with no outline colour to serve as the background for composite 4 .

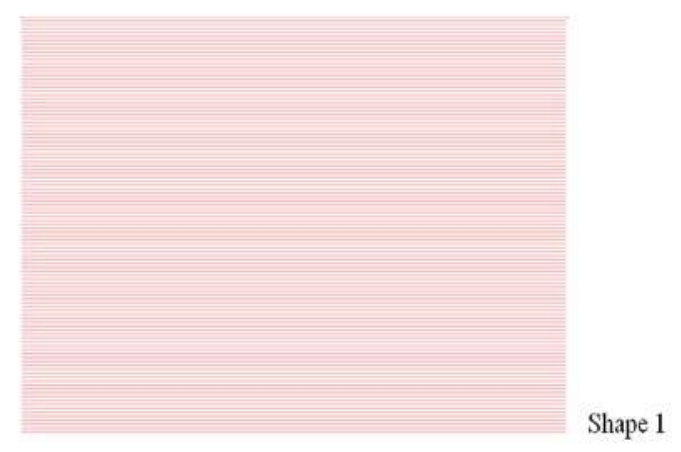

Step 2: Inserting the primary motif

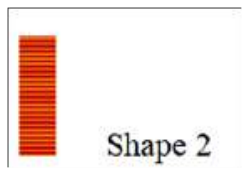

A rectangular shape measuring 0.5 inches high by 0.15 inches wide with a fill colour of brown (shape 2) was inserted at the topmost left corner of shape 1.

Step 3: Duplicating copies of the primary motif 1. Shape 2 was copied, duplicated four times and aligned as shown in group 1 .

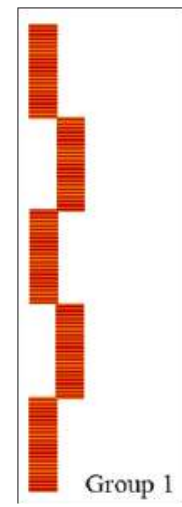

2. The five rectangular shapes (group 1) were regrouped, duplicated and aligned to the right side of each unit. Fifteen repeats were made in all (group 2).

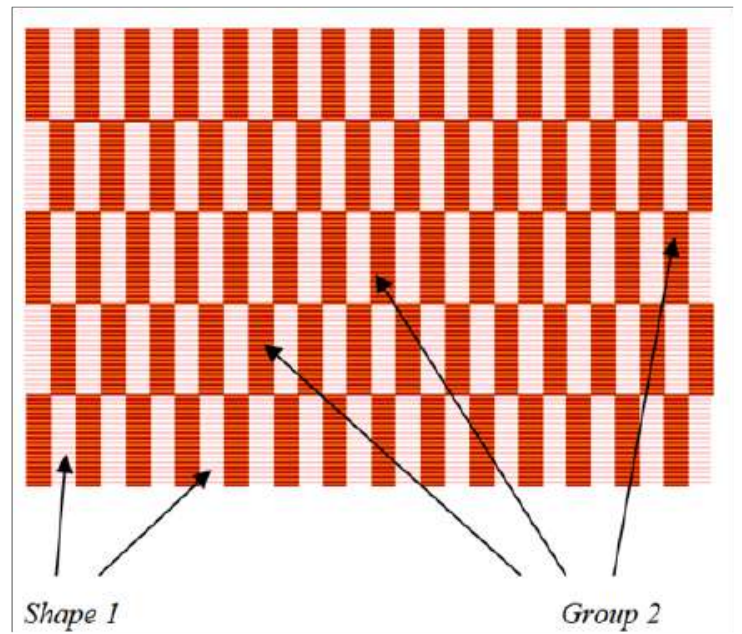


Step 4: Creating the composite motif 4

Finally, the set of repeats (group 2) and the background (shape 1) were grouped together to form the composite motif 4 (Fig 13).

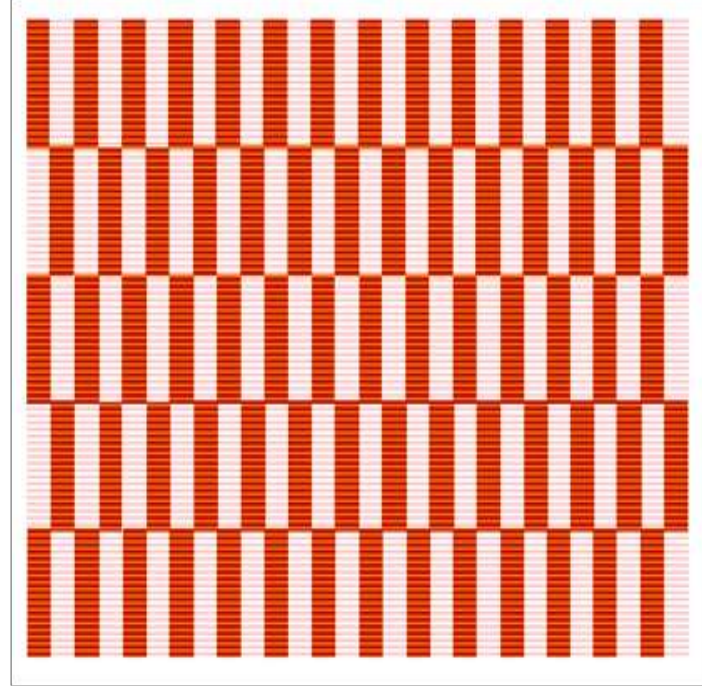

Fig 13: Composite motif 4
Arranging the four composite motifs:

After completing the composite designs, they were arranged on the A4 paper in the document area starting with composite motif 1 at the topmost left corner of the paper followed by the others in alternating repeat fashion. It should be emphasised here that there is no one specific mode for arranging such motifs. The choice of order should be subject to the creative, innovative and imaginative abilities of the designer. These are important innate qualities that every designer must harness in other to enhance originality in his or her design schemes. Fig 14 and fig 15 are two different arrangement patterns from the same composite designs.

\section{RECOMMENDATIONS}

Equipping a student with knowledge in the elements and principles of design offers him or her better foundation for understanding the relationship existing among the elements so they can create relevant and appropriate shapes that fit in a specific design concept. Designers must gain knowledge about the symbolism of colour and shapes within the Akan traditional setting where the kente dominates in its application and be creative in their choice of colours and shapes that synchronise with those symbolic meanings. This is essential in order for people to identify with their designs to increase patronage and foster projects that meet the traditional ideological meanings held in the interpretation of kente.

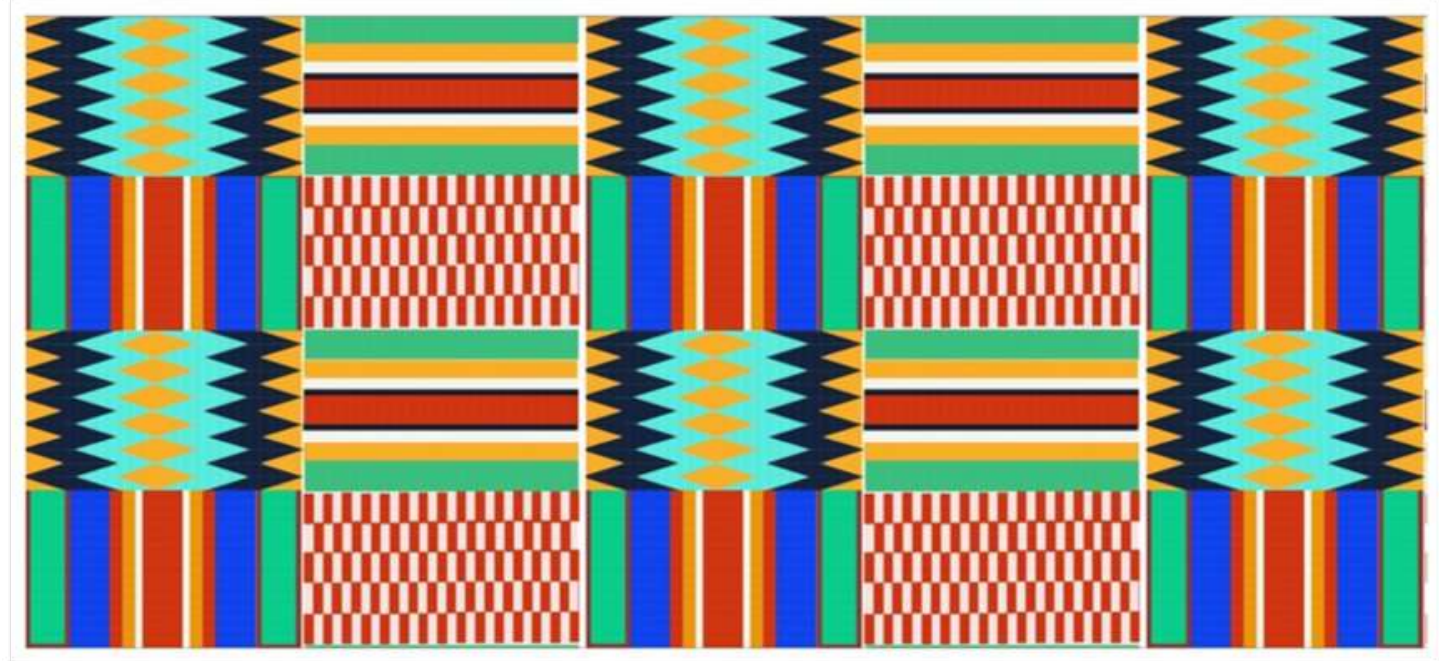

Fig 14: Arranging the composite designs 


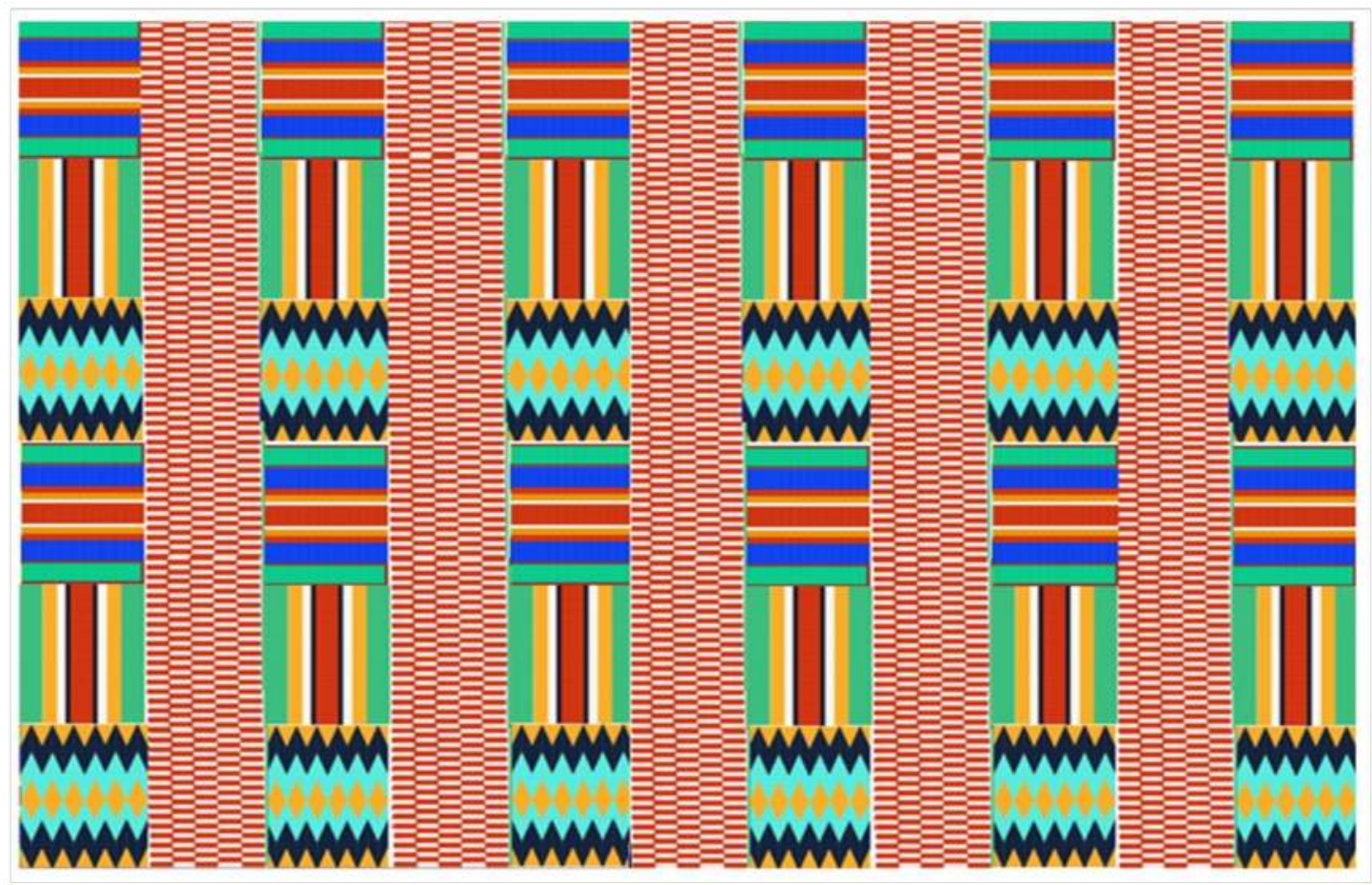

Fig 15: Different pattern arrangement of the same composite design

\section{CONCLUSION}

Computer software like Photoshop and CorelDraw are examples of sophisticated graphic application software developed with exclusive purpose for design work in technical and vocational programmes including textile designing. Unfortunately, their complex design procedures pose a great challenge for students to grasp with ease. The writer in this paper has therefore created the awareness of the level at which kente designing can be heightened with the use of one of the most popular general-purpose application software (Microsoft Word) available to academia. The simplified procedures described in this paper is a revelation that offers the opportunity for textile designers in the creative industry to explore to build the capacity for idea development not only in kente designing but in fabric design as a whole. It is also to serve as a primary manual for Basic and Senior High School Visual Art teachers to adopt for facilitating the design skills of their students. It is the expectation of the researcher that students who will master this idea development skill will be in the position to support their parents in the kente weaving industry in Ghana to enhance their fabric production, and offer them job opportunity in the textile industry after completing their education.

\section{REFERENCES}

Annum, G.Y. (2013). Useful Lessons for Distance Educational Course Writers Lacking Capacity for Interactive Electronic Learning Material Development for the Enhancement of Web-Based Distance Learning. Retrieved September 18, 2017, from (http://beta.garj.org/ garjerr/abstract/2013/November/Annum.htm)

Best, J.W. (1981). Research in Education, Prentice-Hall, Inc. Fourth edition.

Easterday, M.W., Lewis D. R. \& Gerber E. M. (2014). Design-Based Research Process: Problems, Phases, and Applications. Northwestern University, Evanston, IL, Retrieved May 10, 2017, from https:// 


\section{Annum}

egerber.mech.northwestern.edu/wp-content/ uploads/2014/10/

DesignResearch_Methodology_ICLS_2014.pdf

Haag S., Perry J.T., Parker R. \& Wells M. (2002). The I-Series Microsoft Office XP Vol. I Expanded, McGraw-Hill Companies, Inc.

O'Brien J.A. (2003). Introduction to Information Systems: Essentials for the e-Business Enterprise, University of Phoenix Special Edition Series, 11th Edition, McGraw-Hill Companies, Inc.

Poole, B.J. (2010). Essential Microsoft Office 2010: Tutorials for Teachers. Retrieved Sep- tember 16, 2017, from (http://www.pitt.edu/ poole/office2010Tutorials/2010Lesson3.pdf )

Van den Akker, J. (1999). Principles and Methods of Development Research. In J. van den Akker, N. Nieveen, R. M. Branch, K. L. Gustafson \& T. Plomp (Eds.), Design Methodology and Developmental Research in Education and Training, The Netherlands: Kluwer Academic Publishers.

Wales, J. (2015). Wikipedia Free Encyclopaedia, Kente cloth. Retrieved May 10, 2017, from (https://en.wikipedia.org/wiki/Kente_cloth) 